\title{
What's next now that the WHO has declared a COVID-19 pandemic?
}

\author{
Cite as: CMAJ 2020 March 30;192:E349-50. doi: 10.1503/cmaj.1095855
}

Posted on cmajnews.com on March 13, 2020

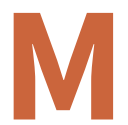

any experts were calling the worldwide outbreak of COVID-19 a pandemic before the World Health Organization (WHO) officially declared a public health emergency of international concern. Dr. Srinivas Murthy, co-chair of the WHO's clinical research committee for the new coronavirus, and Dr. Alon Vaisman, an infectious diseases physician at Toronto General Hospital, explain how the declaration does (and doesn't) change the game.

\section{CMAJ: Why declare a pandemic now?} Why not sooner?

Vaisman: Now, because of the number of transmissions outside of China, there is no doubt that it's a pandemic. And [WHO Director-General Dr. Tedros Adhanom Ghebreyesus] mentioned a lack of response or inaction by some countries to properly manage the virus.

Murthy: The point of declaring a pandemic is to mobilize resources... effectively, it's a poke to the countries of the world who are not doing adequate preparatory work.

\section{CMAJ: Where are response efforts lagging?}

Murthy: I don't want to point fingers at the Americans... but they leave a lot of response efforts to be desired. They need better coordination efforts to make sure they get this under control, and as a country that shares a long border with them, it's in Canada's interest to help them. And then globally, I think there's a lot of interest in the lower-income regions, but there's not enough financial support from higherincome places. We all feel we have to protect ourselves, which is reasonable,

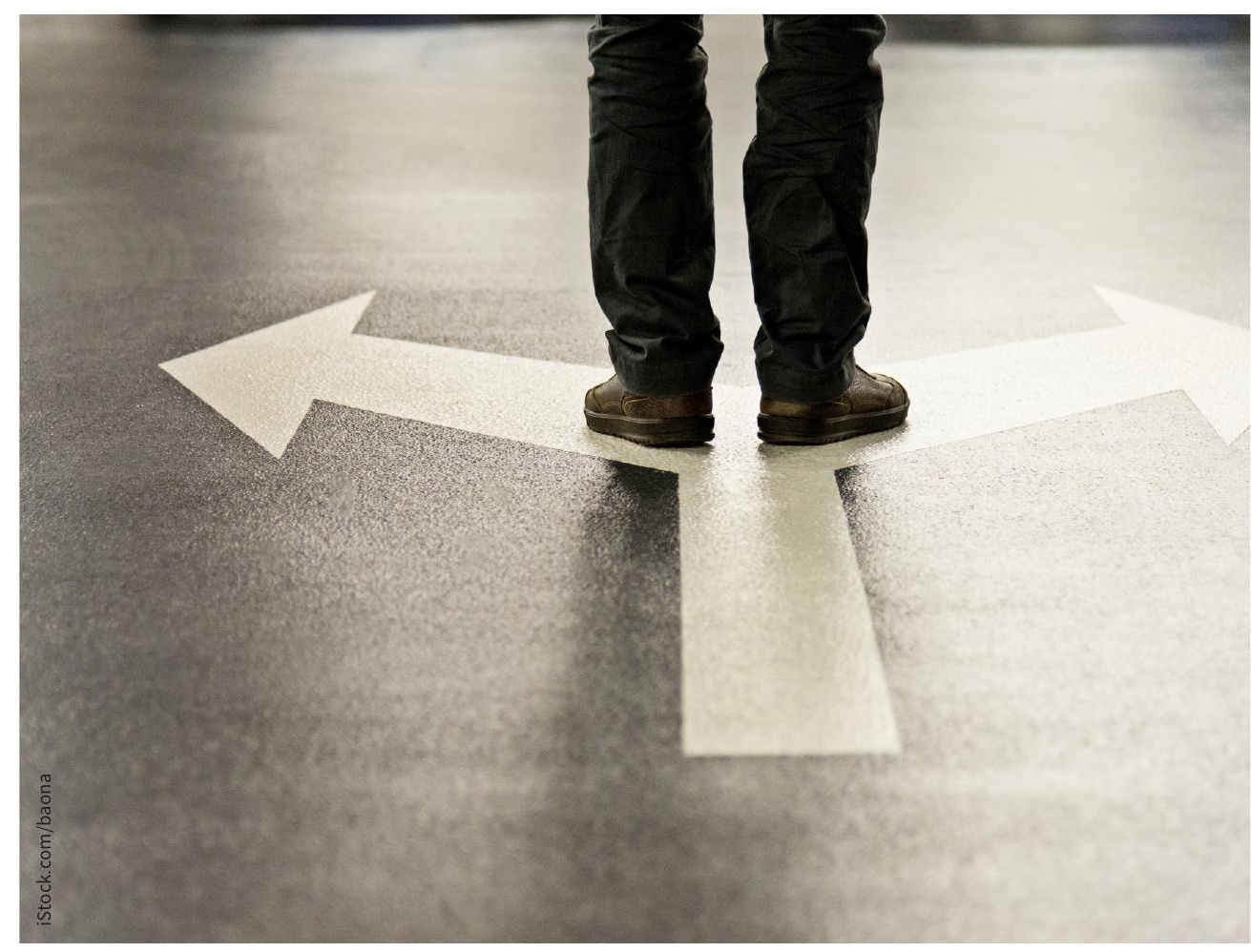

The declaration of a pandemic comes at a critical point for flattening the curve of COVID-19.

but in the context of an outbreak if we don't control it everywhere, we're going to continue to prepare for the worst.

\section{CMAJ: How responsive have we been in Canada?}

Vaisman: In terms of the curve of the epidemic, Canada is a little bit behind all the other countries. Because we haven't seen as many positive cases, it gives us a chance to learn from other countries. The two leading provinces, Ontario and British Columbia, have done all the right things: contract tracing, public education, releasing tests very early and expanding [testing criteria]. Although it may not have been official, we've had the ability across Canada to have a far more liberal approach to testing, and that allowed us to pick up all these cases [acquired outside of China]. That's one of the big differences compared to America, where the community cases were picked up late because of strict definitions and not being able to test everyone.

Murthy: Canada has seen a rapid escalation in efforts at the public health and operational level. Ideally, that would have happened months ago when we first started hearing news and acknowledging that the virus was probably going to spread outside of China. Now that we're having 
more and more cases, I think it's dawning on us that we have to get ready, and our hospitals and health authorities and all the rest are acting.

\section{CMAJ: How will the declaration of a pandemic change Canada's response?}

Murthy: We should have been doing all of these things before that word came out of the mouth of a WHO official, but really it means more coordination, more resources and more attention.

Vaisman: There were already discussions and preparations being made for a long time now, so even when the WHO declared a global health emergency, it didn't really change things. There was a report from the Prime Minister that was released simultaneously with the announcement, so that was being planned anyhow, and the federal COVID-19 committee was already established. All the various regional bodies across Canada have been set up to try to figure out ways to prevent local transmission, to offload emergency departments and acute care facilities. All that was going on, even before the pandemic was declared.

\section{CMAJ: What should our next steps be?}

Vaisman: The important thing that is being done and should be done is preparation on the acute care side to have the resources, ventilators, medications, tubing ready. If you think about the population of Canada being affected in the same numbers that we saw in Hubei or Italy or Iran, it's going to overwhelm the system... We need to get creative doing things to improve capacity.
Lots of our inpatients are waiting for longterm care beds; that needs to be prioritized. And a lot of people come to emergency departments completely unnecessarily when they could have gone [to other services] if there was a little more availability. [Some] people don't have advanced directives on their charts about resuscitation; that needs to be updated so we don't do advanced life support for people who don't want it or haven't considered that they don't want it. All sorts of things like that, always in the background, need to be wrapped up.

\section{CMAJ: Other than the pandemic} declaration, are there any other major shifts in response you've seen in the past week?

Murthy: The first few cases of community spread are notable in Canada. We hadn't had that yet, and we'll see what happens if those are contained or not.

Vaisman: In Canada, one big shift is that there's a wider range of people being tested, and the discussion about setting up specific clinics away from hospitals to get tested, those kinds of things are game changers, because you offload the emergency departments. And the really big change that's coming now is the social distancing. People are very quickly understanding this. Events, concerts, movies and sporting events are being cancelled; that's huge and you would think this would have taken people a long time to wrap their heads around, but people are quickly understanding how important it is.

Lauren Vogel, CMAJ 